\title{
Effect of the pitch angle and of the number of blades on depression created under impellers
}

\author{
Corina Băbuţanu ${ }^{1}$, and Lucian Mândrea ${ }^{2, *}$ \\ ${ }^{1}$ National Research Institute for Electrical Engineering ICPE-CA, Efficiency in Energy Conversion \\ and Consumption Department, 313 Splaiul Unirii, Bucharest, Romania \\ ${ }^{2}$ University Politehnica of Bucharest, Department of Hydraulics, Hydraulic Machinery and \\ Environmental Engineering, 313 Splaiul Independentei, Bucharest, Romania
}

\begin{abstract}
This work presents a set of experiments concerning the behavior of several types of impellers regarding the depression formatted and operating in a specific range of rotations. Various mixer designs including a four pitched blades impeller, a six flat blades impeller and four two flat blades impeller were compared. Experimental data confirmed the analytical results previously obtained. The results showed that there are similarities regarding the effects generated by four pitched blades impeller and one of the two flat blades impeller. Also, it is found that two shortblade impeller produces the lowest depression of all tested impeller. The maximum depression produced by all type of impellers do not exceeds 120 $\mathrm{mmH}_{2} \mathrm{O}$ at $400 \mathrm{rpm}$, which is a small value to realize the vaporization of the fluid and to reach the cavitation. The equipment is not in danger to be destroyed. The numerical results obtained by experiments can be used in various practical applications.
\end{abstract}

\section{Introduction}

From extractive and food industry and up to newest industries, like aerospace industry or pharmaceutical, impellers, stirrers or mixers are widely used for homogenization multiphase mixtures, acceleration of chemical reactions or movement of substances through devices and equipment. Beside issues related to energy and/or environmental impellers use raises also issued related to depression appeared behind the moving blades. Depending on the physical and chemical characteristics of the substances involved in industrial processes, depression which occurs at impellers operation and its dimension are factors with negative potential effects, like slowing of movement, vortices that tend to lower the degree of homogeneity, etc. Given the practical importance of the issue, there are many studies which approach both theoretical and experimental study of the phenomenon, in order to remove possible undesirable effects [1-4]. Analytical approaches are quite rapidly but not very accurately, while numerical solutions can be more precise but are more complicated and time consuming.

The authors of this work previously obtained an original analytical solution used to calculate the depression which appears during operation of the impellers. It was obtained

\footnotetext{
*Corresponding author: mandrea lucian@hotmail.com
} 
the radius variation in the depression area, the pressure inside the depression zone and the depression height [5]. The problem was also studied in [6], the author obtaining a formula that calculates the height of the depression area.

The maximum radius of the depression zone at the contact level between the impeller and the water is $[5,7,8]$ :

$$
R=\sqrt{\frac{2}{\rho \varepsilon^{2} t^{2}}\left(p_{e}-p_{v}\right)}
$$

In the space under the impeller in rotation, the pressure inside the depression zone becomes smaller than the exterior pressure (the light blue area). The exterior pressure of the water is the $p_{e}$ in the blue area. $\varepsilon$ is the tangential acceleration and $\rho$ the water density. $t$ is the time variable.

Using variable radius $r$, one can calculate the pressure inside the depression zone:

$$
p=p_{e}-\frac{\rho \varepsilon^{2} t^{2}}{2} r^{2}
$$

The height of the rotation paraboloid from figure 1 is:

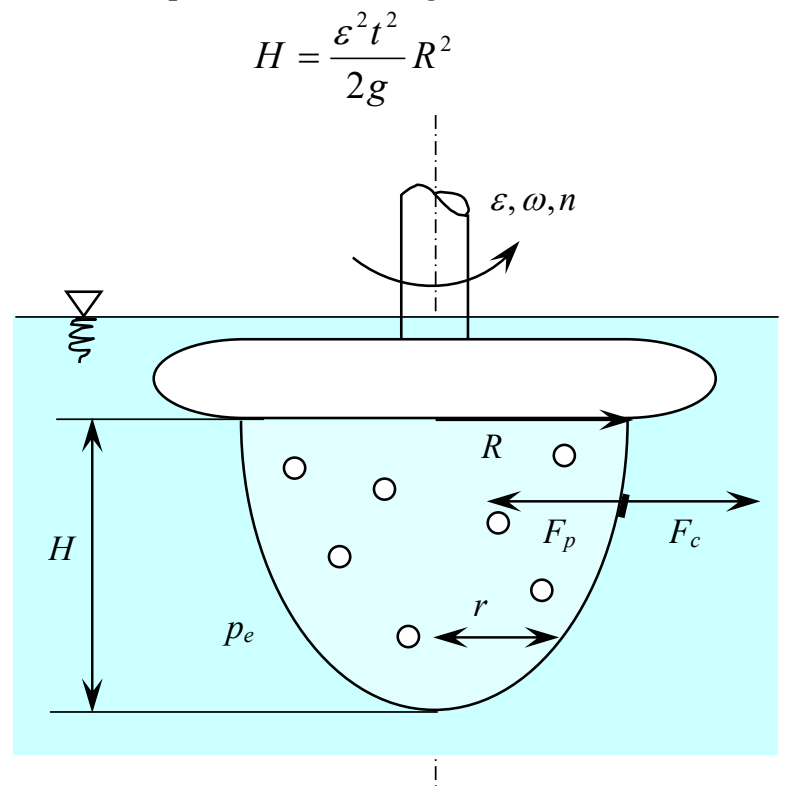

Fig. 1. Characteristics of the depression zone created under impeller.

\section{Materials and methods}

In order to obtain supplementary data concerning depression caused by impeller operation, a new set of experimental measurement was made. The aim of these measurements was to determine the influence of the type of impeller on the depression size. Experiments were conducted in an experimental setup that is shown in Figure 2 a. It consists of a transparent cylindrical vessel with the ratio $\mathrm{D} / \mathrm{H}$ of about 1.5 and a capacity of $0.126 \mathrm{~m}^{3}$. Equipment is endowed with a variable speed motor on whose shaft can be fitted impellers of different types and sizes. Also, the setup is equipped with electronic speed control, and a panel 
which displays rotational speed and momentum produced by the studied impellers. To measure the depression caused by the impellers, a pressure plug is mounted at a distance of $120 \mathrm{~mm}$ from the vessel bottom.

The seven types of impellers are shown in Figure $2 \mathrm{~b}$.

The experiments were made utilizing tap water under normal pressure and temperature.

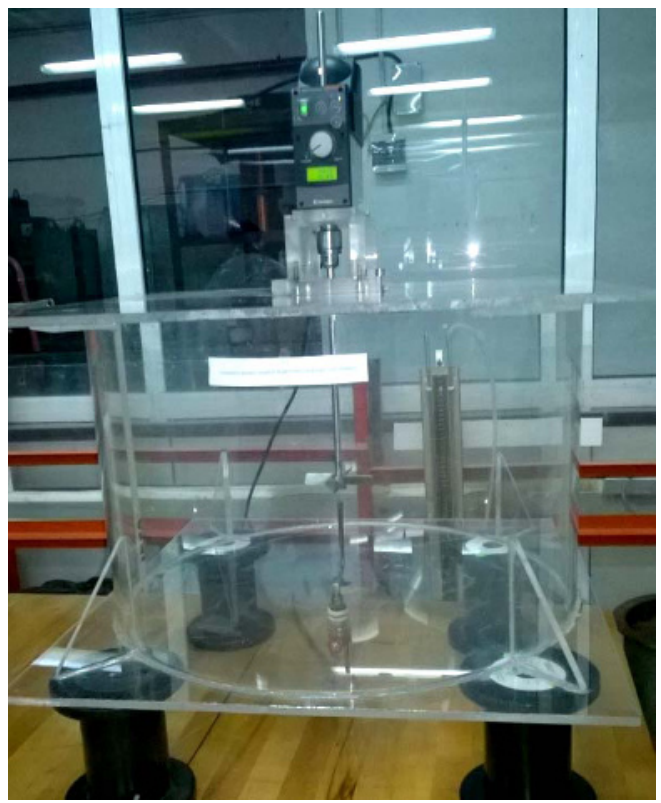

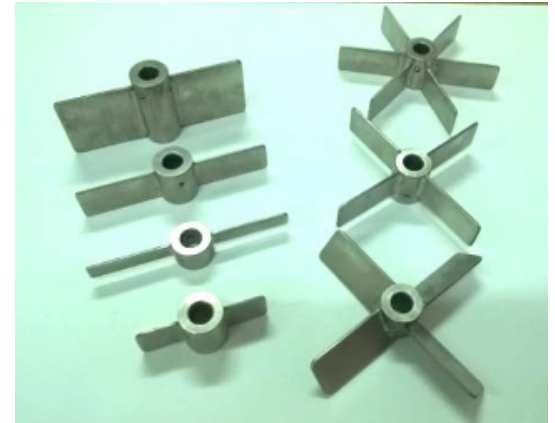

b.

a.

Fig. 2. The first experimental setup (a) and the tested impellers (b).

Seven types of impellers (four impellers with two flat blades, an impeller with four flat blades, an impeller with four pitched blades, and an impeller with six flat blades) were tested in a speed range between 100 and $500 \mathrm{rpm}$. All the impellers had a hub diameter of $20 \mathrm{~mm}$ and blades size as follows:

- $\quad$ two thin flat blades impeller - $100 \mathrm{~mm}$ length and $10 \mathrm{~mm}$ width;

- $\quad$ two flat blades impeller - $100 \mathrm{~mm}$ length and $20 \mathrm{~mm}$ width;

- $\quad$ two wide flat blades impeller - $100 \mathrm{~mm}$ length and $40 \mathrm{~mm}$ width;

- $\quad$ two short flat blades impeller - $60 \mathrm{~mm}$ length and $20 \mathrm{~mm}$ width;

- $\quad$ four flat blades impeller - $100 \mathrm{~mm}$ length and $20 \mathrm{~mm}$ width;

- $\quad$ four pitched blades $\left(45^{\circ}\right.$ pitch angle) impeller $-100 \mathrm{~mm}$ length and $20 \mathrm{~mm}$ width;

- $\quad$ six flat blades impeller - $100 \mathrm{~mm}$ length and $20 \mathrm{~mm}$ width.

The depression $\Delta \mathrm{H}$ (expressed in $\mathrm{mmH}_{2} \mathrm{O}$ ) was measured in five different positions of impellers who were located vertically at $10,20,30,40$ respectively $50 \mathrm{~mm}$ from the pressure plug. Its evolution for each type of impeller is shown in figures 3-7.

\section{Results and discussion}

Analyzing the diagrams obtained from testing the seven propellers some observations regarding their behavior can be made. Thus, it appears that for the impellers with blades having the same dimensions, as the number of blades increases, the greater is the depression (two flat blades impeller, four flat blades impeller and two flat blades impeller). It also notes that, for the impeller with the same diameter the depression increases with an 
increased width of impeller (two thin flat blades impeller, two flat blades impeller and two wide flat blades impeller). Similarly, for the impeller of the same width, diameter increase lead to increased depression (two flat blades impeller and two flat short blades impeller).

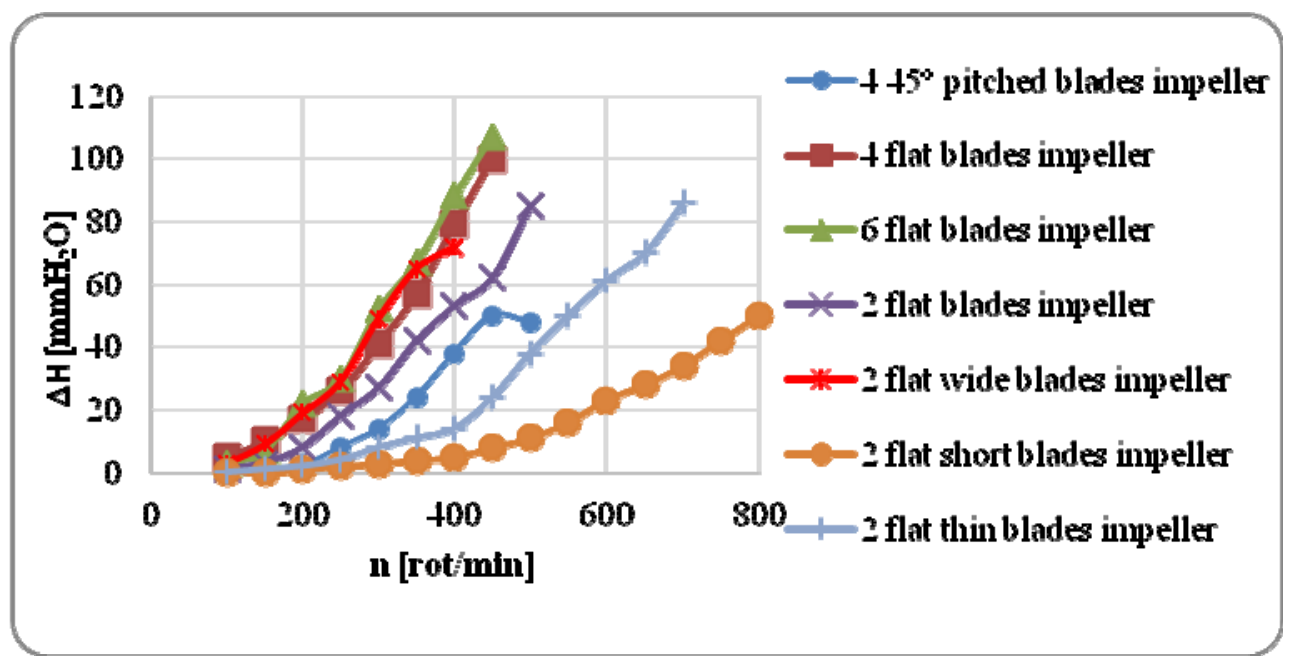

Fig. 3. Variation of depression produced at $10 \mathrm{~mm}$ from bottom impeller.

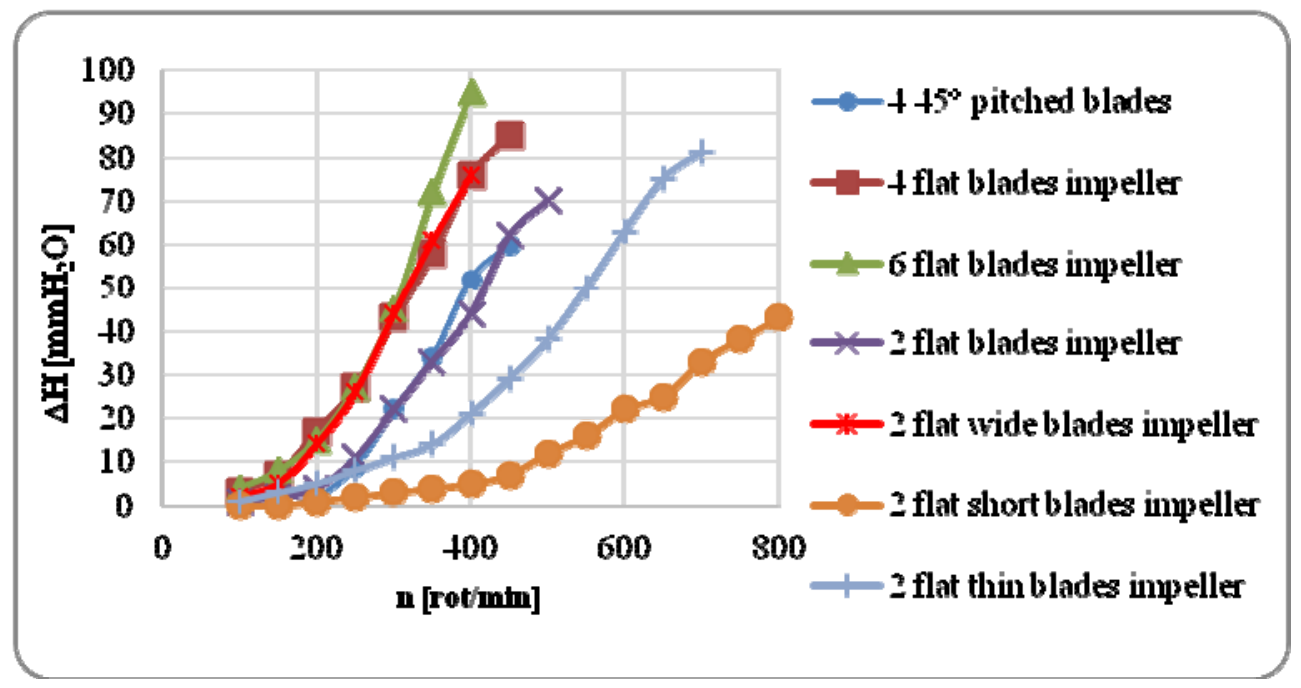

Fig. 4. Variation of depression produced at $20 \mathrm{~mm}$ from bottom impeller. 


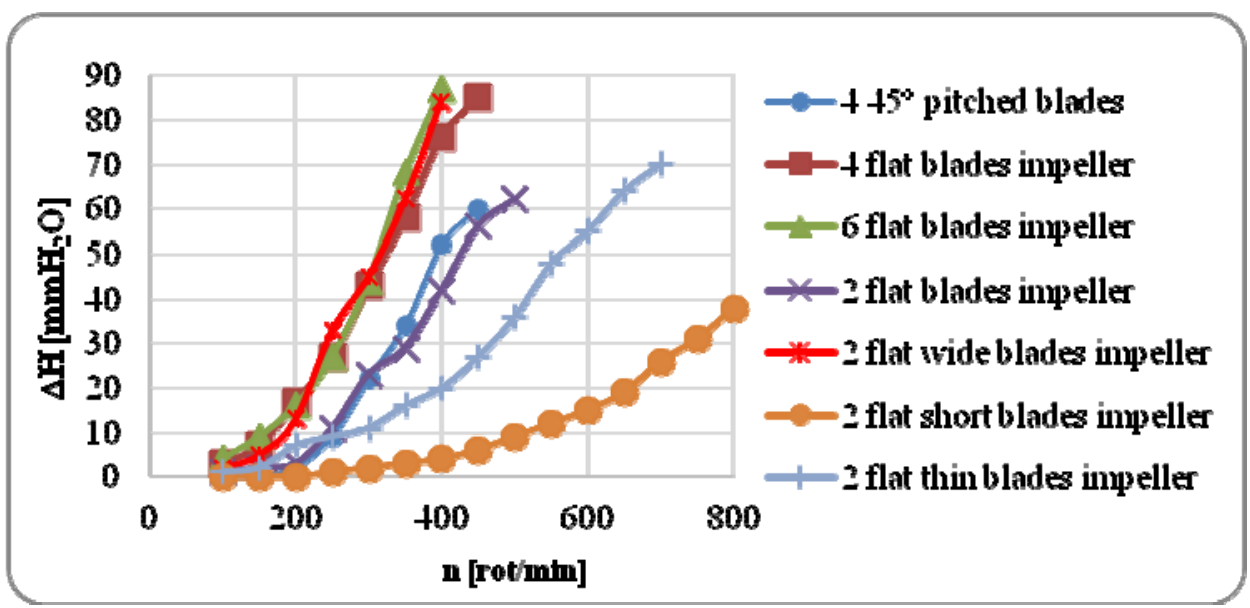

Fig. 5. Variation of depression produced at $30 \mathrm{~mm}$ from bottom impeller.

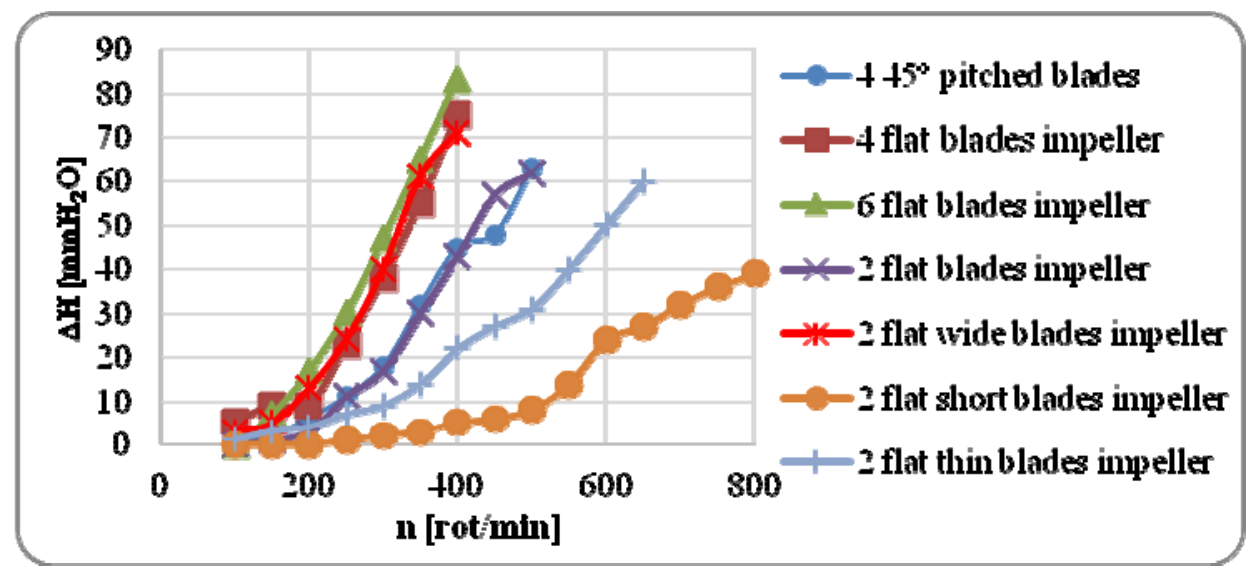

Fig. 6. Variation of depression produced at $40 \mathrm{~mm}$ from bottom impeller.

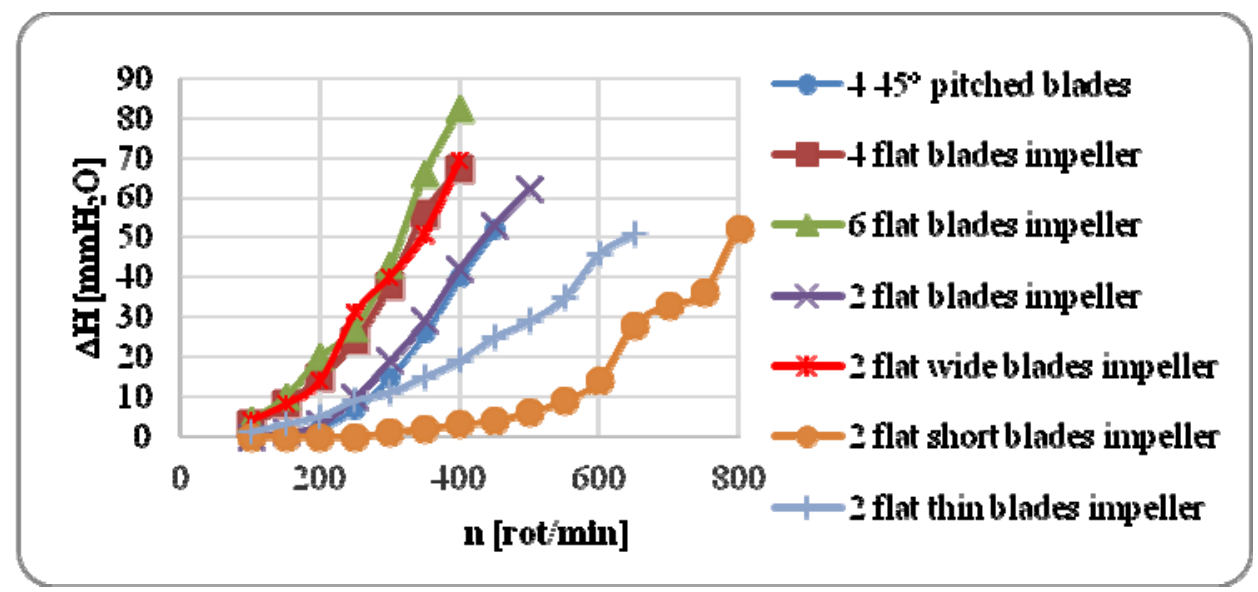

Fig. 7. Variation of depression produced at $50 \mathrm{~mm}$ from bottom impeller. 
In all of the five measuring points it was found that the depression caused by the two flat blades impeller is quasi identical with the one caused by the four $45^{\circ}$ pitch blades impeller.

Also in the range between 100 and $400 \mathrm{rpm}$ is observed that the depression created by the six flat blades impeller, four flat blades impeller and four $45^{\circ}$ pitch blades impeller is almost similar. We also note that short-bladed impeller produces a depression much lower than all the other types.

Regarding the distance between the impeller and the measuring point, there is a decrease of depression with increasing distance, which confirms theoretical approach (see Figure 1).

\section{Conclusions}

The present work shows that the impeller type plays an important role on the depression size it can create. Although many of the conclusions were expected results, these experiments have quantified the depression created by the operation of these propellers. Depending on the reaction mode on different operating conditions (pressure, viscosity, temperature, etc.) tested equipment can be used in various practical applications.

From the figure 3 to figure 7 it is very clear that the depression expressed by $\Delta H$ increases as the rotating speed increases, thing in correspondence with the theoretical part (formula number 2).

The maximum depression produced by all type of impellers do not exceeds $120 \mathrm{mmH}_{2} \mathrm{O}$ at $400 \mathrm{rpm}$ in our case, which is in fact a small value to realize the vaporization of the fluid and to reach the cavitation. The equipment is not in danger to be destroyed.

The research was conducted within NUCLEUS Program, contract no. 14N/2016, Innovative solutions regarding the design and implementation of hydrokinetic turbines financed by the Romanian Executive Agency for Higher Education, Research, Development and Innovation Funding.

\section{References}

1. K. Souidi, A. Mardaru, M. Roudet, A. Marcat, D. Della Valed, G. Djelveh, Che. Eng., Sci., 74, 9, (2012)

2. C. Hsiao, A. Jain, G.L. Chahine, Proc. of $26^{\text {th }}$ Symposium on Naval Hydrodynamics Rome, 26, 12 (2006)

3. Z. Trad, C. Vial, J.-P. Fontaine, C. Larroche, Che. Eng. Sci. (to be published)

4. J. Bin, L. Xian-wu, W. Yu-lin, L. Shu-hong, X. Hong-yuan, O. Akira, J. of Hydrodynamics 22(5), 6 (2010)

5. L. Mândrea, G. Oprina, C. Băbuţanu, D. Marin, G. Negreanu, Applied Mechanics and Materials 841, 6 (2016)

6. P.R.N. Childs, Rotating Flow, (Butterworth Heinemann Elsevier, 2010)

7. L. Mândrea, C. Cipu, S. Cănănău, World Renewable Energy Congress Bucharest Romania (2015)

8. L. Mândrea, C. Băbuţanu, G. Oprina, G. Militaru, Proc. of $20^{\text {th }}$ Innovative Manufacturing Engineering and Energy Conference IManEE 2016, IOP Conference Series Materials and Engineering, 161, 6 (2016) 